\title{
The Impact of Securities Margin Trading on Chinese Stock Market
}

\author{
Shaozhen Chen ${ }^{1}$, Liang $\mathrm{Su}^{1}, \mathrm{Li} \mathrm{Lin}^{2}$, Chaoqun Zhou ${ }^{1} \&$ Haohui $\mathrm{Lin}^{3}$ \\ ${ }^{1}$ Finance Department of International Bussiness School, Jinan University, Zhuhai, Guangdong Province, China \\ ${ }^{2}$ Business Management of International Bussiness School, Jinan University, Zhuhai, Guangdong Province, China \\ ${ }^{3}$ School of Electrical and Information, Jinan University, Zhuhai, Guangdong Province, China \\ Correspondence: Shaozhen Chen, Finance Department of International Business School, Jinan University, \\ Qianshan Road 206\#, Zhuhai City, Guangdong Province, Post No. 519070, China. Tel: 86-131-1235-5361. \\ E-mail: 1813012994@qq.com
}

Received: January 17, 2018

doi:10.5539/ijef.v10n4p101
Accepted: February 3, 2018

Online Published: March 5, 2018

URL: https://doi.org/10.5539/ijef.v10n4p101

\begin{abstract}
In this paper, we take Shanghai Stock Market as the research object, conducts a multi-dimensional analysis of the volatility of the Shanghai Stock Exchange 50 Index before and after the introduction of margin trading. After the implementation of the securities margin trading policy, the historical volatility of the securities market has obviously been weakened. From the perspective of dynamic volatility, we establish a GARCH $(1,1)$ model by introducing the dummy variables according to the AIC and SC optimal rules, and establish TGARCH $(1,1)$, EGARCH $(1,1)$ and PGARCH $(1,1)$ to analyze the asymmetry. All of the model results show that the introduction of margin trading reduces the risk of the stock market and weakens the asymmetry. In order to test the effect of the residual distribution of returns, we assume that the residuals follow the t distribution and the GED distribution respectively and establish the optimal GARCH $(1,1)$ model. The final result is the same as those under the Gaussian distribution assumption.
\end{abstract}

Keywords: dynamic volatility, asymmetry, GARCH models, residual distribution

\section{Introduction}

Compared with Europe and the United States, China's margin trading system officially began in 2010, which makes the securities market more active, to some extent, promoted the development of China's stock market. However, China's stock market experienced a catastrophic decline in 2015. There are many reasons behind the sharp shrinkage of financial market value. Whether the issues of securities margin trading can help reduce the risk in the securities market has been widely discussed by scholars. Currently, the impact of the margin trading on the stock market volatility is mainly concluded in the following three points.

The first view is that securities margin trading has no significant effect on market volatility. Figlewski, Stephen, and Webb (1993) concluded that there was no interaction between the short selling of securities and the volatility of the stock market. Battalio and Schultz (2006) studied the Internet bubble that emerged in 1999 and 2000 in NASDAQ. The study found that there was no significant fluctuation in the price of internet stock when the short selling was restricted. While Staff and Sigurdsson (2010) studied tens of thousands of stocks in 26 countries, they found that there was a very small probability of extreme losses in the stock return rate. That was, the two financial services had no specific impact on the stock market volatility. Xiaoshan (2011) empirically investigated the Chinese stock market through the VAR (vector auto-regression) model and the Granger causality test. The results showed that since the launch of margin trading mechanism, the impact was still weak in more than one year, without significant effect on volatility and liquidity. Xiaopeng (2012) conducted empirical tests using econometric methods such as Granger causality test, impulse response function, and variance decomposition. The results showed that the marging trading had no significant effect on the stock market volatility.

The second view is that margin trading business can play a role in inhibiting market fluctuations. The result of James (1997) showed that the root cause of the stock price volatility in the securities market was not the introduction of the short selling mechanism. On the contrary, the short-selling would stabilize the stock market volatility to a limited extent. Ekkehart and Julie (2012) proposed that the short sale mechanism improved the information efficiency of the price through empirical evidence. The stock prices were more accurate when short sellers were more active, which largely reduced post-earnings-announcement drift for negative earnings surprises. 
That was, the introduction of short selling was conducive to stabilizing the market. Xiao and Kong (2014) examined the effects and mechanisms of margin trading on the stock price volatility based on the double-difference model. The study found that margin trading reduced the price volatility of the underlying securities, but this effect was achieved by reducing the noise trading of the underlying securities, increasing the speed of information transmission, reducing the company's earnings manipulation and reducing the information asymmetry between investors, which proved that the margin trading business reduced the non-information efficiency of stock's volatility.. Menghua (2015) used 710 underlying stock data and used VAR method to study separately the impact of margin trading on the stock market and individual stock volatility from two perspectives of the stock market and individual stocks. Empirical results showed that margin trading could significantly reduce the volatility of the stock market.

The third view is that margin trading on the stock market volatility plays a role in fueling. Bogen and Kroos (1961) argued that the leverage effect of margin trading made the demand and supply greatly increase when the stock price went up and down. As a result, the actual price of the stock tended to deviate excessively from its true value. Haruvy and Noussair (2006) studied the volatility of stock prices under the constraint of the two-trading system and open restriction. Empirical evidence showed that stock prices tended to be overestimated under the constraints, and the stock price under open constraints can easily be underestimated. This showed that the two-financial business was prone to a stock market bubble, resulting in greater market risk. Miaoxin and Zhenlong (2008) based on the Hong Kong market research have verified when asset prices were overvalued, short selling constraints would further increase the asset price level and volatility. Guoping and Shen (2015) used the GARCH model and VAR model with dummy variables to empirically test the volatility of the stock market before and after the introduction of margin trading business and the impact of margin trading on stock market volatility. The results showed that the margin trading business exacerbated the stock market volatility.

In summary, scholars mostly establish a single model from the perspective of stock market information efficiency. Few papers have been reported on the impact of margin trading on the market based on the volatility. Therefore, this paper selects the transaction data of the Shanghai Stock Exchange 50 Index from 2005 to 2017. Taking the formal implementation of the margin financing and securities lending policy in 2010 as the node, this paper establishes a GARCH model from the perspectives of the historical volatility and the dynamic volatility to examine the impact of margin trading on the stock market volatility. Finally, we summarize the results of the empirical research, put forward reasonable suggestions on the existing problems in margin trading of the securities market, and provide a reference for the financial regulatory authorities to manage the securities market.

\section{Volatility Models}

Volatility is a measure of how much the price indicator vibrates up and down the mean. We construct different volatility models to study stock price volatility.

\subsection{Historical Volatility}

There are many ways to calculate historical volatility. We choose several frequently used methods to characterize the historical volatility of stock prices, such as Close to Close (CtC), Parkinson, Garman-Klass and Rogers-Satchell volatility.

\subsubsection{Close to Close}

$\mathrm{CtC}$ is one of the most widely used volatility models and is defined as the annualized standard deviation of logarithmic return. The general expression for $\mathrm{CtC}$ is

$$
\left\{\begin{array}{l}
x_{i}=\operatorname{Ln}\left(\frac{c_{i}}{c_{i-1}}\right) \\
s_{x}=\sqrt{\frac{1}{N}} \sqrt{\sum_{i=1}^{N}\left(x_{i}-\bar{x}\right)^{2}} \\
\sigma_{x}=s_{x} \times \sqrt{\frac{N}{N-1}} \\
\text { Volatility }_{C t C}=\sigma_{C t C}=\sqrt{\frac{1}{N-1}} \sqrt{\sum_{i=1}^{N}\left(x_{i}-\bar{x}\right)^{2}}
\end{array}\right.
$$

Where $C_{i}$ is the daily closing price 


\subsubsection{Parkinson}

This is the first advanced volatility estimator created by Parkinson in 1980, instead of using closing prices it uses the high and low price. While other measures are more efficient based on simulated data, some studies have shown this to be the best measure for actual empirical data. The model can be shown as

$$
\text { Volatility }_{\text {Parkinson }}=\sigma_{P}=\sqrt{\frac{1}{N}} \sqrt{\frac{1}{4 \operatorname{Ln}(2)} \sum_{i=1}^{N}\left(\operatorname{Ln}\left(\frac{h_{i}}{l_{i}}\right)\right)^{2}}
$$

Where $h_{i}$ is the highest daily price; $l_{i}$ is the daily lowest price; $o_{i}$ is the daily opening price.

\subsubsection{Garman-Klass}

Garman-Klass volatility estimator was created in 1980. It is an extension of Parkinson which includes opening and closing prices. The formula can be expressed as:

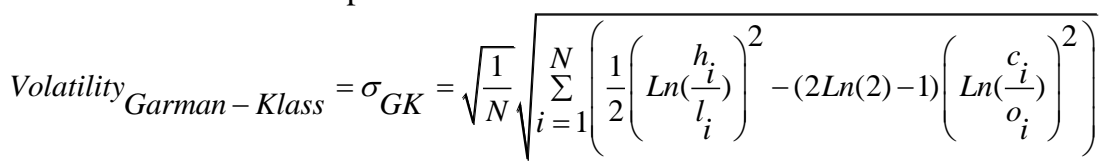

\subsubsection{Rogers-Satchell}

The efficiency of the Rogers-Satchell estimate is similar to that for Garman-Klass, however, it benefits from being able to handle non-zero drift. It can be shown as

$$
\text { Volatility }_{\text {Rogers }- \text { Satchell }}=\sigma_{R S}=\sqrt{\frac{1}{N}} \sqrt\left[\sum_{i=1}^{N}\left(\operatorname{Ln}\left(\frac{h_{i}}{c_{i}}\right) \operatorname{Ln}\left(\frac{h_{i}}{o_{i}}\right)+\operatorname{Ln}\left(\frac{l_{i}}{c_{i}}\right) \operatorname{Ln}\left(\frac{l_{i}}{o_{i}}\right)\right]{)}\right.
$$

\subsection{Dynamic Volatility}

One of the basic assumptions of historical volatility is that the yield residuals follow a normal distribution. However, many scholars based on the normal distribution hypothesis empirical study results obtained deviate from the actual situation, so some people think that the yield residual sequence does not meet the normal distribution, but a skewed distribution. In recent years, many studies have been conducted on the asymmetric features and fluctuations of financial time series. The results all support the assumption of non-normal distribution, which reflects the general understanding of the academic community.

GARCH model is a commonly used model for studying financial time series. So far, a variety of sub-models have been developed for different situations. The dynamic volatility, which is characterized by different GARCH models, takes into account the asymmetric and aggregative characteristics of financial time series and can reflect the actual situation of price volatility well. Here are some common GARCH models.

\subsubsection{GARCH (p, q)}

GARCH model is an extension of the ARCH model, proposed by T.Bollerslev in 1986, which is suitable for the analysis and prediction of volatility. The expression of $\operatorname{GARCH}(\mathrm{p}, \mathrm{q})$ is shown as

$$
\left\{\begin{array}{l}
y=x_{t}^{\prime} \varphi+u_{t}, u_{t} \sim N\left(0, \sigma_{t}^{2}\right) \\
\sigma_{t}^{2}=\omega+\sum_{i=1}^{p} \alpha_{i} u_{t-i}^{2}+\sum_{j=1}^{q} \beta_{j} \sigma_{t-j}^{2}
\end{array}\right.
$$

Where $\omega>0, \alpha_{i} \geq 0, \beta_{i} \geq 0, \sum_{i=1}^{p} \alpha_{i}+\sum_{j=1}^{q} \beta_{i}<1$

\subsubsection{TGARCH (p, q)}

The TGARCH model can reflect the asymmetry of financial market volatility and is proposed independently by Zokian (1990) and Glosten et al. (1993). The expression of TGARCH (p, q) is shown as

$$
\left\{\begin{array}{l}
y=x_{t}^{\prime} \varphi+u_{t}, u_{t} \sim N\left(0, \sigma_{t}^{2}\right) \\
\sigma_{t}^{2}=\omega+\sum_{i=1}^{p} \alpha_{i} u_{t-i}^{2}+\sum_{j=1}^{q} \beta \sigma_{j-j}^{2}+\gamma u_{t-1}^{2} I_{t-1}
\end{array}\right.
$$

Where $I_{t-1}$ is a dummy variable and satisfies 


$$
\left\{\begin{array}{l}
I_{t-1}=0, u_{t-1} \geq 0 \\
I_{t-1}=1, u_{t-1}<0
\end{array}\right.
$$

When $u_{t-1} \geq 0$, it represents a positive external shock (good news); when $u_{t-1}<0$, it represents a negative external shock (bad news), and if $\gamma \neq 0$, it represents a significant impact of external shocks on volatility, and if $\gamma>0$, it represents a leverage effect on volatility.

\subsection{3 $\operatorname{EGARCH}(\mathrm{p}, \mathrm{q})$}

Nelson (1991) put forward the EGARCH model, which could also reflect the asymmetry of financial market volatility. The expression of $\operatorname{EGARCH}(p, q)$ is shown as

$$
\left\{\begin{array}{l}
y=x_{t}^{\prime} \varphi+u_{t}, u_{t} \sim N\left(0, \sigma_{t}^{2}\right) \\
\ln \sigma_{t}^{2}=\omega+\sum_{k=1}^{r} \theta_{k} \frac{u_{t-k}}{\sigma_{t-k}}+\sum_{i=1}^{p} \alpha_{i} \frac{\left|u_{t-i}\right|}{\sigma_{t-i}}+\sum_{j=1}^{q} \beta_{j} \ln \sigma_{t-j}^{2}
\end{array}\right.
$$

When $\theta \neq 0$, it shows that the impact of external shocks on the fluctuation is asymmetric; when $\theta<0$, it shows that the price volatility of financial products is more affected by external shocks than by external shocks, that is, "leverage effect".

\subsubsection{PGARCH (p, q)}

The PGARCH model is attributed to the study of Taylor (1986), Schwert (1989) and Ding, Granger, and Engle (1993), which is also an asymmetric GARCH model. The expression of PGARCH (p, q) is shown as

$$
\left\{\begin{array}{l}
y=x_{t}^{\prime} \varphi+u_{t}, u_{t} \sim N\left(0, \sigma_{t}^{2}\right) \\
\sigma_{t}^{h}=\omega+\sum_{i=1}^{p} \alpha_{i}\left|u_{t-i}\right|-\gamma_{i} u_{t-i}{ }^{h}+\sum_{j=1}^{q} \beta_{j} \ln \sigma_{t-j}^{h}
\end{array}\right.
$$

Where $h>0$; when $i=1,2,3, \ldots, r,\left|\gamma_{i}\right| \leq 1$; In another case, $\gamma_{i}=0$ and it requires the number of thresholds does not exceed $p$. If the fluctuations are symmetric, then $\gamma_{i}=0$ for $i$, and $\gamma_{i} \neq 0$ when there exists a leverage effect.

\section{Empirical analysis}

\subsection{Data Selection and Description}

In the empirical part, we choose the Shanghai Stock Market as the research object. The daily price data is selected from January 1, 2005, to March 1, 2017. All of the sample data comes from the Wind database. In order to see the influence of margin trading, we divide the data into two group, one is from January 1, 2005, to March 31, 2010; the other is from April 1, 2010, to March 1, 2017. In addition, these two groups are both contain the bull market, bear market and normal market, which is better in measuring the role of margin trading mechanism in the extreme situation.

\subsection{Historical Volatility}

Actually, the volatility will be translated into an annualized volatility. Therefore, we make all the results are annual type by multiplying a constant value. According to equations above, historical volatilities of the sample are shown as follow.
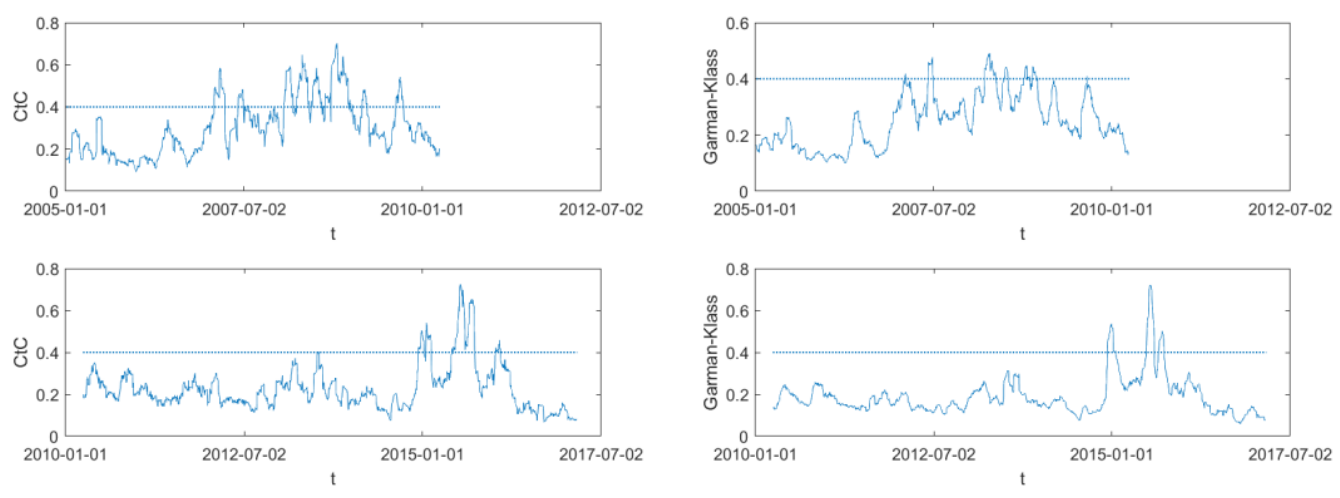

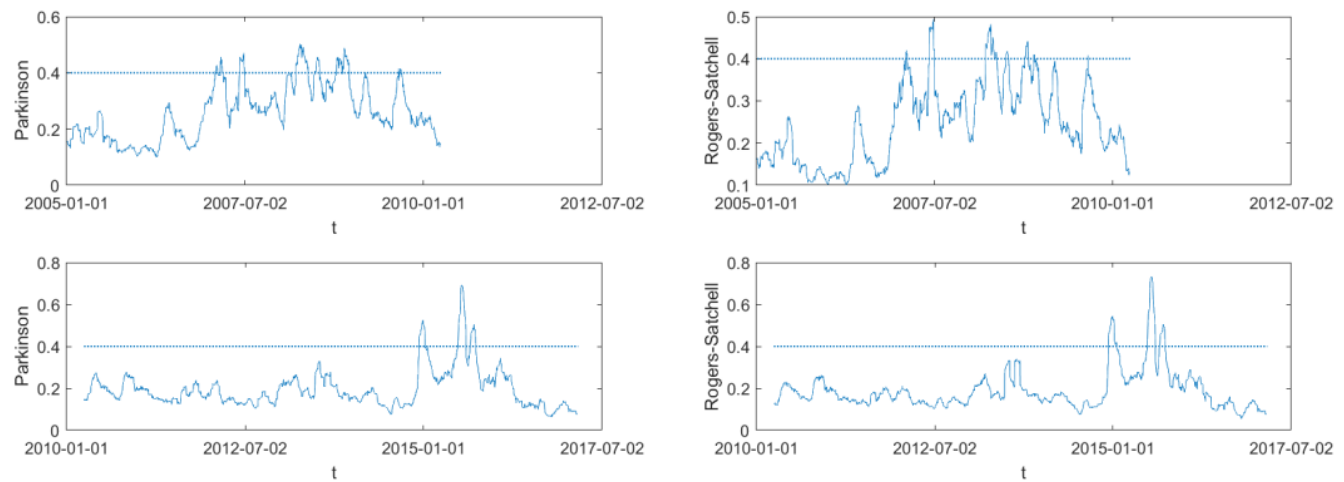

Figure 1. Historical volatilities of the Shanghai stock market

Based on the results calculated above, before the launch of margin trading policy, the volatility of the stock market is higher and breaking through the threshold we set at 0.4; after March 31, 2010, the volatility of the stock market significantly declined. However, we find that once the stock market crash in China in 2015, the stock market volatility once again significantly exceed the threshold. This shows that to a certain extent, margin trading can reduce the volatility of the stock market. The poor performance in extreme situations may be related to the market sentiment.

In order to better examine the relationship between volatility and earnings, we can plot the relationship between risk (volatility) and return (log return). As can be seen from Figure 2, the risk is more concentrated after the launch of the policy, and the margin trading has a stable market effect.
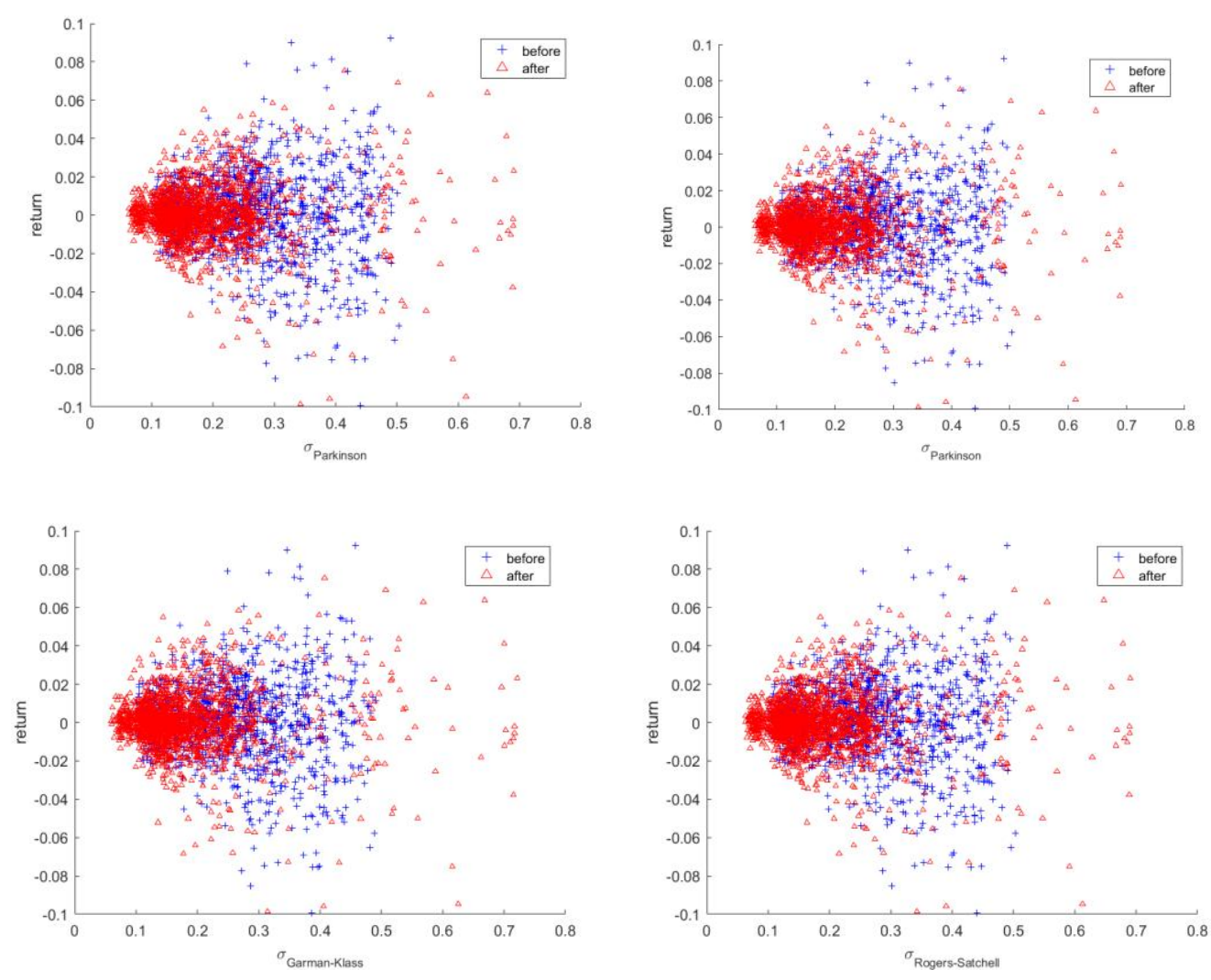

Figure 2. Risk comparison before and after the implementation of margin trading 


\subsection{Dynamic Volatility}

\subsubsection{Model Assumptions}

1). Margin trading can weaken the market volatility;

2). Margin trading can weaken the market asymmetry.

\subsubsection{Descriptive Statistics}

We plot the logarithmic return series of the SSE 50 index. Obviously, there exist minor amplitudes following large amplitudes, and the risk is continuous.

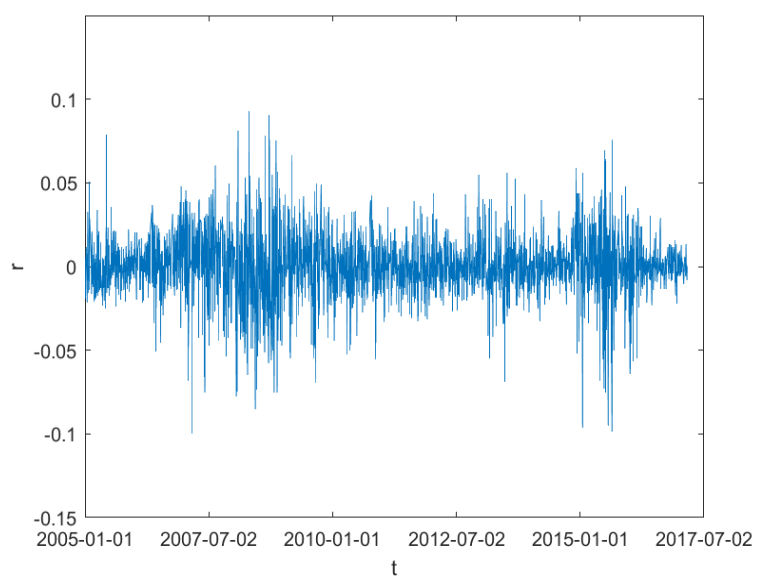

Figure 3. SSE 50 index logarithmic returns

From the perspective of logarithmic return series, it is obvious that time series contains fluctuation clustering effect. To further test whether the series follows the normal distribution, this paper uses the JB test the result shows the return series does not obey normal distribution but obeys an asymmetrical distribution.

Table 1. Descriptive statistics of returns

\begin{tabular}{cccccccccc}
\hline Sample & Mean & Median & Maximum & Minimum & Std.Dev. & Skewness & Kurtosis & JB & Prob.(JB) \\
\hline All & 0.000351 & 0.000342 & 0.0923 & -0.0995 & 0.0184 & -0.3109 & 6.6251 & 1663.923 & 0.0000 \\
Before & 0.000812 & 0.001191 & 0.0923 & -0.0994 & 0.0212 & -0.2535 & 5.3054 & 295.3117 & 0.0000 \\
After & $8.5 \mathrm{e}-07$ & -0.00027 & 0.0755 & -0.0985 & 0.0160 & -0.4366 & 8.1054 & 1877.946 & 0.0000 \\
\hline
\end{tabular}

\subsubsection{Stability Test}

In order to avoid false returns, we first test the stability of the time series. Using the ADF unit root test, we testify the longitude return of SSE 50 Index and its result is shown in the Table 2. Before and after the MT reform, the ADF statistics of time series are all less than the critical value and it is stable enough.

Table 2. The result of ADF test

\begin{tabular}{cccc}
\hline & \multicolumn{3}{c}{ Test Critical Values } \\
\cline { 2 - 4 } Sample & $1 \%$ & $5 \%$ & $10 \%$ \\
\hline Augumented D-F test Statistic & -12.3353 & -7.3566 & -7.9479 \\
All & -2.5658 & -1.9409 & -1.6166 \\
Before & -2.5668 & -1.9411 & -1.6165 \\
After & -2.5663 & -1.9410 & -1.6165 \\
\hline
\end{tabular}

\subsubsection{Autocorrelation Test and Pattern Recognition}

We do the autocorrelation test on the logarithmic return of SSE 50, as it is shown in table 3, according to the P value, we choose one of these equation as the mean equation.

$$
\begin{aligned}
& \ln r_{t}=\rho \ln r_{t-4}+u_{t} \\
& \ln r_{t}=\rho \ln r_{t-6}+u_{t}
\end{aligned}
$$


Table 3. Autocorrelation test and partial correlation test results

\begin{tabular}{ccccccc}
\hline \multirow{2}{*}{$\begin{array}{c}\text { Sample } \\
\text { Lag }\end{array}$} & \multicolumn{3}{c}{ All } & \multicolumn{2}{c}{ Before } & \multicolumn{2}{c}{ After } \\
\cline { 2 - 7 } & Q-state & Prob & Q-state & Prob & Q-state & Prob \\
\hline 1 & 0.2556 & 0.613 & 0.0355 & 0.851 & 0.3087 & 0.578 \\
2 & 1.4624 & 0.481 & 0.2425 & 0.886 & 1.8933 & 0.388 \\
3 & 2.4861 & 0.478 & 1.2445 & 0.742 & 1.9295 & 0.587 \\
4 & 14.588 & 0.006 & 5.8005 & 0.215 & 9.7021 & 0.046 \\
5 & 14.872 & 0.011 & 6.0100 & 0.305 & 9.7736 & 0.082 \\
6 & 30.715 & 0.000 & 12.365 & 0.054 & 19.901 & 0.003 \\
7 & 33.093 & 0.000 & 12.670 & 0.081 & 23.470 & 0.001 \\
12 & 38.336 & 0.000 & 19.378 & 0.080 & 32.481 & 0.001 \\
24 & 69.055 & 0.000 & 40.780 & 0.018 & 84.901 & 0.000 \\
\hline
\end{tabular}

The regression results are shown in Table 4. According to AIC and SC minimum guidelines, we choose equation (2) to be the mean equation and then to find out whether it suitable for building the GARCH model.

Table 4. Regression result

\begin{tabular}{ccccccc}
\hline & \multicolumn{2}{c}{ All } & \multicolumn{2}{c}{ Before } & \multicolumn{2}{c}{ After } \\
\cline { 2 - 7 } & $(1)$ & $(2)$ & $(1)$ & $(2)$ & $(1)$ & $(2)$ \\
\hline Prob. $(\rho)^{2}$ & 0.0005 & 0.0001 & 0.0293 & 0.0140 & 0.0050 & 0.0014 \\
$R^{2}$ & 0.0038 & 0.0049 & 0.0022 & 0.0033 & 0.0047 & 0.0060 \\
AIC & -5.1504 & -5.1510 & -4.8686 & -4.8683 & -5.4308 & -5.4321 \\
SC & -5.1484 & -5.1503 & -4.8671 & -4.8643 & -5.4276 & -5.4289 \\
\hline
\end{tabular}

As can be seen in Table 5, the $\mathrm{P}$ values of $\mathrm{F}$ statistic and Chi-square statistic are all less than 0.05 , so there exists the ARCH effect in the model and we further establish the GARCH model.

Table 5. ARCH effect test result

\begin{tabular}{cccc}
\hline Sample & All & Before & After \\
\hline Prob. F & 0.0000 & 0.0001 & 0.0000 \\
Prob. Chi-Square(1) & 0.0000 & 0.0001 & 0.0000 \\
\hline
\end{tabular}

\subsubsection{The Establishment of GARCH Model}

The empirical research based on GARCH model generally assumes that the residual obeys the Gaussian distribution and then compares it with other distributional assumptions. We also follow the same paradigm.

\subsubsection{Gaussian Distribution Hypothesis}

The commonly used GACH model in practice is GARCH $(1,1)$, GARCH $(1,2)$ and GARCH $(2,2)$, which have a good fitting effect and a wide range of applications. Firstly, we assume that the residuals follow the Gaussian distribution and then estimate them separately (Table 6). Finally, we establish a GARCH $(1,1)$ model based on the test indicators.

Table 6. Model test results (Gaussian distribution)

\begin{tabular}{cccc}
\hline Prob. & GARCH $(1,1)$ & GARCH $(1,2)$ & GARCH $(2,1)$ \\
\hline$\rho$ & 0.0046 & 0.0043 & 0.0039 \\
$\omega$ & 0.0001 & 0.0030 & 0.0000 \\
$\alpha_{1}$ & 0.0000 & 0.0002 & 0.0269 \\
$\alpha_{2}$ & - & - & 0.0012 \\
$\beta_{1}$ & 0.0000 & 0.0000 & 0.0000 \\
$\beta_{2}$ & - & 0.2182 & - \\
$\mathrm{AIC}$ & -5.4206 & -5.4205 & -5.4213 \\
$\mathrm{SC}$ & -5.4125 & -5.4103 & -5.4112 \\
\hline
\end{tabular}


(1) The Impact of Margin Trading on Volatility

In examining the impact of margin trading on volatility, we introduce dummy variables into the variance equation to establish the following equation:

Dummy variable D meets:

$$
\left\{\begin{array}{l}
\ln r_{t}=\rho \ln r_{t-6}+u_{t}, u_{t} \sim N\left(0, \sigma_{t}^{2}\right) \\
\sigma_{t}^{2}=\omega+\alpha_{1} u_{t-1}^{2}+\beta_{1} \sigma_{t-1}^{2}+\lambda D
\end{array}\right.
$$

$$
\left\{\begin{array}{l}
D=0, \text { before the introduction of margin trading } \\
D=1, \text { after the introduction of margin trading }
\end{array}\right.
$$

To make an estimate and we get:

$$
\left\{\begin{array}{l}
\ln r_{t}=-0.0552 \ln r_{t-6}+\varepsilon_{t} \\
\sigma_{t}^{2}=0.0000023+0.0564 \varepsilon_{t-1}^{2}+0.9401 \sigma_{t-1}^{2}-0.00000099 D
\end{array}\right.
$$

Table 7. The significance of the variable test results

\begin{tabular}{cccccc}
\hline & $\rho$ & $\omega$ & $\alpha_{1}$ & $\beta_{1}$ & $\lambda$ \\
\hline Prob. & 0.0049 & 0.0001 & 0.0000 & 0.0000 & 0.0434 \\
\hline
\end{tabular}

At the 5\% significance level, the coefficients of the dummy variables passed the significance test. $\lambda<0$, which means the reform can suppress volatility.

(2) The Impact of Margin Financing on Asymmetry

Firstly, we examine the impact of margin trading on the asymmetry of the stock market and compare the estimated test results of the different asymmetric GARCH models (Table 8).

Table 8. Test results of asymmetric GARCH model

\begin{tabular}{ccccc}
\hline Prob. & GARCH(1,1) & TGARCH(1,1) & EGARCH $(1,1)$ & PGARCH $(1,1)$ \\
\hline$\rho$ & 0.0046 & 0.0049 & 0.0077 & 0.0082 \\
$\omega$ & 0.0001 & 0.0001 & 0.0000 & 0.1603 \\
$\alpha_{1}$ & 0.0000 & 0.0000 & 0.0000 & 0.0000 \\
$\theta$ & - & - & 0.0605 & - \\
$\beta_{1}$ & 0.0000 & 0.0000 & 0.0000 & 0.0000 \\
$\gamma_{1}$ & - & 0.3567 & - & 0.1422 \\
AIC & -5.420631 & 5.420094 & -5.423643 & -5.422493 \\
SC & -5.412501 & -5.409930 & -5.413480 & -5.410297 \\
\hline
\end{tabular}

The test of the asymmetric coefficient of EGARCH $(1,1)$ model is significant, which shows that there is a certain asymmetry overall, while the other asymmetric coefficients of GARCH model are insignificant but close to $10 \%$ critical value. Considering the influence of different sample segments, we estimate the sample segments before and after the launch of margin trading (Table 9). The asymmetric coefficient test before the launch of the margin trading business passes, however, the post-launch test fails. This shows that the margin trading helps to weaken

\begin{tabular}{|c|c|c|c|c|c|c|}
\hline \multirow{2}{*}{ Prob. } & \multicolumn{2}{|c|}{$\operatorname{EGARCH}(1,1)$} & \multicolumn{2}{|c|}{$\operatorname{TGARCH}(1,1)$} & \multicolumn{2}{|c|}{ PGARCH $(1,1)$} \\
\hline & Before & After & Before & After & Before & After \\
\hline$\rho$ & 0.0371 & 0.1027 & 0.0259 & 0.0924 & 0.0401 & 0.0936 \\
\hline$\omega$ & 0.0000 & 0.0000 & 0.0029 & 0.0002 & 0.0025 & 0.0009 \\
\hline$\alpha_{1}$ & 0.0000 & 0.0000 & 0.0000 & 0.0000 & 0.0000 & 0.0000 \\
\hline$\theta$ & 0.0041 & 0.3983 & - & - & - & - \\
\hline$\beta_{1}$ & 0.0000 & 0.0000 & 0.0000 & 0.0000 & 0.0000 & 0.0000 \\
\hline$\gamma_{1}$ & - & - & 0.0351 & 0.9889 & 0.0067 & 0.4491 \\
\hline AIC & -5.0821 & -5.6719 & -5.0769 & -5.6717 & -5.0813 & -5.6706 \\
\hline $\mathrm{SC}$ & -5.0618 & -5.6558 & -5.0692 & -5.6556 & -5.0737 & -5.6545 \\
\hline
\end{tabular}
the stock market asymmetry.

Table 9. Test results of the asymmetric GARCH model (before and after) 


\section{(3) Markowitz features}

Then we look at the volatility curve and the distribution of returns and risks. To better fit the volatility, we use the EGARCH $(1,1)$ to estimate the margin before it is launched, and the $\operatorname{GARCH}(1,1)$ after the launch (Table 10). The estimation result is as follows:

$$
\begin{aligned}
& \left\{\begin{array}{l}
\ln r_{t}=-0.0509 \ln r_{t-6}+\varepsilon_{t} \\
\ln \sigma_{t}^{2}=-0.1547+0.1279 \frac{\left|u_{t-1}\right|}{\sigma_{t}}-0.0084 \frac{u_{t-1}}{\sigma_{t}}+0.9927 \ln \sigma_{t-1}{ }^{2}
\end{array}\right. \\
& \left\{\begin{array}{l}
\ln r_{t}=-0.0438 \ln r_{t-6}+\varepsilon_{t} \\
\sigma_{t}^{2}=0.0000016+0.0598 u_{t-1}^{2}+0.9353 \sigma_{t-1}^{2}
\end{array}\right.
\end{aligned}
$$

Table 10. Parameter test result of the GARCH model

\begin{tabular}{cccc}
\hline Prob. & GARCH $(1,1)$ & GARCH $(1,2)$ & $\operatorname{GARCH}(2,1)$ \\
\hline $\boldsymbol{\rho}$ & 0.0897 & 0.0902 & 0.0809 \\
$\omega$ & 0.0002 & 0.0093 & 0.0000 \\
$\boldsymbol{\alpha}_{\mathbf{1}}$ & 0.0000 & 0.0048 & 0.2259 \\
$\boldsymbol{\alpha}_{2}$ & - & - & 0.0023 \\
$\boldsymbol{\beta}_{\mathbf{1}}$ & 0.0000 & 0.0000 & 0.0000 \\
$\boldsymbol{\beta}_{\mathbf{2}}$ & - & 0.3502 & - \\
$\mathrm{AIC}$ & -5.6729 & -5.6723 & -5.6736 \\
$\mathrm{SC}$ & -5.6599 & -5.6561 & -5.6574 \\
\hline
\end{tabular}

The volatility curve and the income risk distribution as shown in Figure 4. It is easy to find the volatility has been more stable and the risk has become more concentrated after the launch of margin financing.
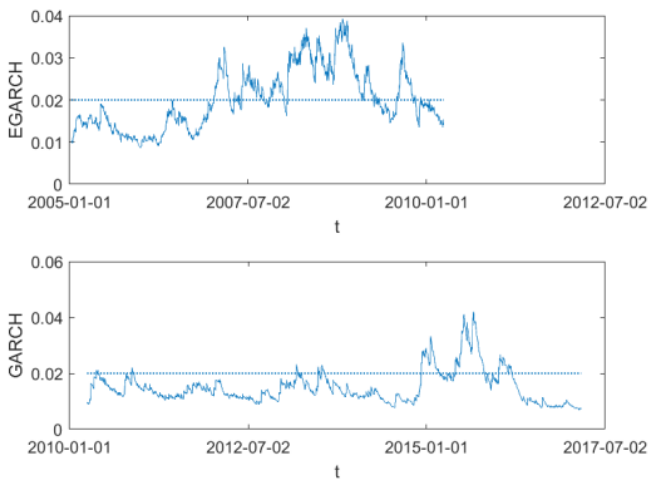

Figure 4. Markowitz features before and after (based on EGARCH and GARCH model)

Finally, we test the ARCH sequence with a lag order of one for the residual sequence (Table 11). The test results show that the GARCH model is stable.

Table 11. The result of the ARCH effect test

\begin{tabular}{cccc}
\hline & EGARCH-All & EGARCH-Before & GARCH-After \\
\hline Prob. F & 0.3343 & 0.5676 & 0.2692 \\
Prob. Chi-Sq (1) & 0.3341 & 0.5672 & 0.2690 \\
\hline
\end{tabular}

\subsubsection{T Distribution and GED Distribution Hypothesis}

Based on the assumption of t-distribution and GED distribution, we establish the different asymmetric GARCH models. The estimation equations are as follows, 


$$
\begin{aligned}
& \left\{\begin{array}{l}
\ln r_{t}=-0.0497 \ln r_{t-6}+\varepsilon_{t} \\
\sigma_{t}^{2}=0.0000031+0.0592 \varepsilon_{t-1}^{2}+0.9403 \sigma_{t-1}^{2}-0.0000021 D \\
\varepsilon_{t} / \sigma_{t} \sim t(4.56)
\end{array}\right. \\
& \left\{\begin{array}{l}
\ln r_{t}=-0.0412 \ln r_{t-6}+\varepsilon_{t} \\
\sigma_{t}^{2}=0.0000028+0.0571 \varepsilon_{t-1}^{2}+0.9391 \sigma_{t-1}^{2}-0.0000017 D \\
\varepsilon_{t} / \sigma_{t} \sim G E D(1.19)
\end{array}\right.
\end{aligned}
$$

Compared with the Gaussian distribution hypothesis, the estimation accuracy of the GARCH models (t-distribution and GED distribution) has been improved (Table 12).

Table 12. Comparison of test results (Gaussian, student-t, GED)

\begin{tabular}{cccc}
\hline & GARCH-Gaussian & GARCH-t & GARCH-GED \\
\hline AIC & -5.4208 & -5.4901 & -5.4968 \\
SC & -5.4106 & -5.4778 & -5.4846 \\
\hline
\end{tabular}
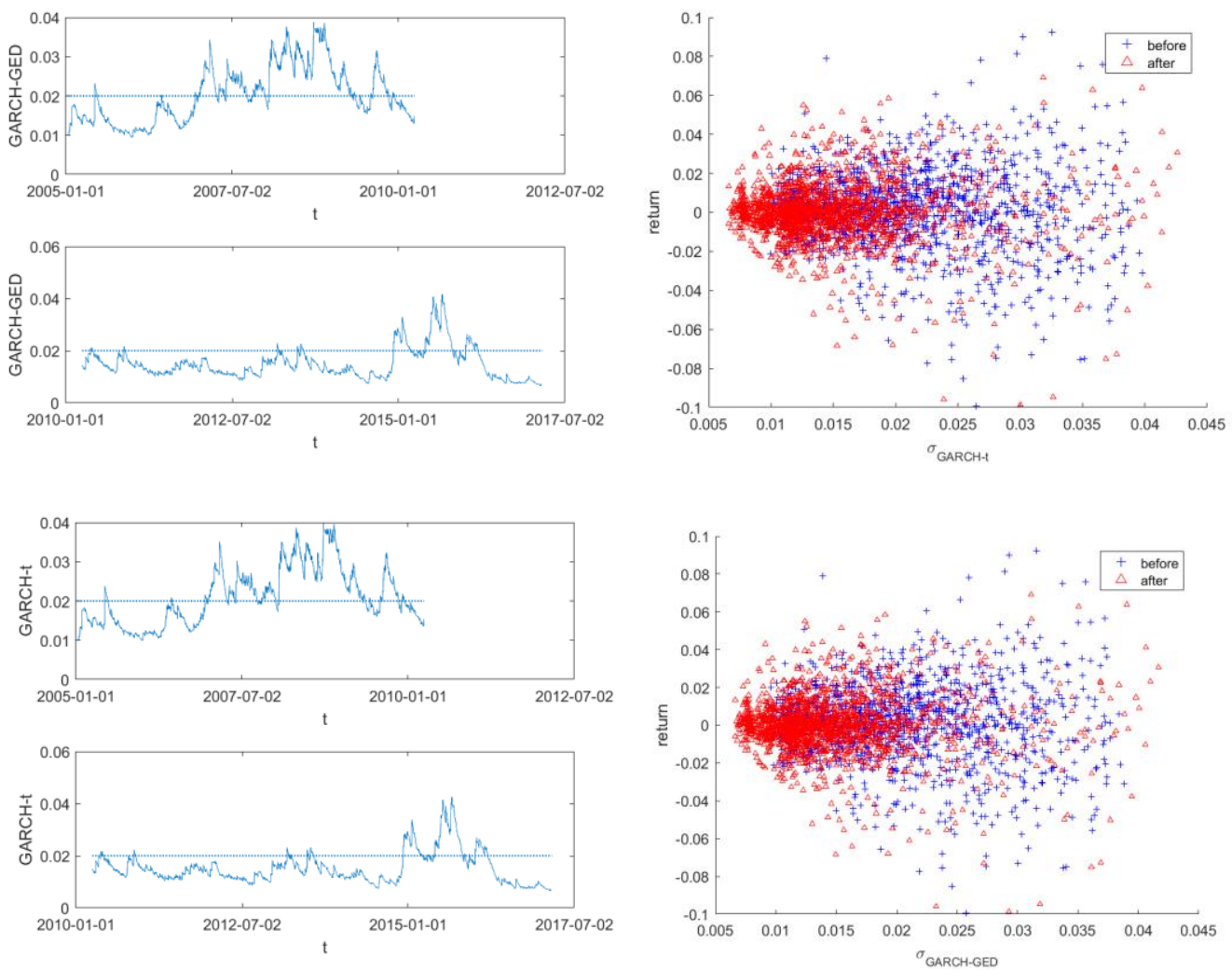

Figure 5. Markowitz features before and after (student-t, GED)

\section{Conclusions and Policy Recommendations}

Margin financing is regarded as an important tool for stabilizing the securities market. Since it was introduced, margin trading has received wide attention. However, whether it plays a real role in stabilizing the market is still need to be verified. This paper empirically analyzes the impact of margin trading on volatility and asymmetry. From the historical volatility and dynamic volatility two perspectives, we draw the conclusions as follows:

(1) After the introduction of margin trading market volatility significantly weakened, the risk is more concentrated, but in extreme circumstances, there may be the role of helping sell to sell down

(2) Market volatility and asymmetry after the introduction of margin trading significantly weakened, the risk is more concentrated. Margin trading can play a role in curbing volatility

In financial regulation, we make the following suggestions: 
(1) Improve the regulatory system

Chinese securities market has a relatively short period of development, market operation mechanism is not perfect and market participants lack awareness of self-discipline. Margin trading, as a new thing, need external regulation and intervention. Government regulatory departments should be combined with industry self-regulation to prevent the emergence of systemic risks.

(2) Strengthen investment bank internal control

Regulators can set a minimum percentage of cash guarantees, and investment banks also have the flexibility to adjust to their own circumstances so as to better manage their own risks.

\section{References}

Angel, J. J. (1997). Short selling on the NYSE. Georgetown University.

Battalio, R., \& Schultz, P. (2006). Options and the Bubble. Journal of Finance, 61(5), 2071-2102. https://doi.org/10.1111/j.1540-6261.2006.01051.x

Boehmer, E., Fong, K., \& Wu, J. (2012). International Evidence on Algorithmic Trading. Social Science Electronic Publishing.

Bogen, J. I., \& Krooss, H. E. (1961). Security credit : its economic role and regulation. The Journal of Finance, 16(3), 443-444. https://doi.org/10.2307/2977341

Figlewski, S., \& Webb, G. P. (1993). Options, Short Sales, and Market Completeness. Journal of Finance, 48(2), 761-777. https://doi.org/10.1111/j.1540-6261.1993.tb04738.x

Gammoudi, I., Ghourabi, M. E., \& Belkacem, L. (2016). Value-at-risk bounds for multivariate heavy tailed distribution: An application to the Glosten-Jagannathan-Runkle generalized autoregressive conditional heteroscedasticity model. The Journal of Risk Model Validation. https://doi.org/10.21314/jrmv.2016.157

Guoping, W., \& Shen, G. (2015). An Empirical Study on the Impact of Margin Trading on the Volatility of China's Stock Market. Price:Theory \& Practice, 10, 105-107.

Hao, X., \& Ai-guo, K. (2014). Study on the Mechanism of the Impact of Margin Trading on Stock Price Characteristic Volatility: Test Based on Double Difference Model. Management World, 8, 30-43; 187-188.

Haruvy, E., \& Noussair, C. N. (2006). The Effect of Short Selling on Bubbles and Crashes in Experimental Spot Asset Markets. Journal of Finance, 61(3), 1119-1157. https://doi.org/10.1111/j.1540-6261.2006.00868.x

Lapinova, S., \& Saichev, A. (2012). Comparative statistics of Garman-Klass, Parkinson, Roger-Satchell and bridge estimators. Papers. https://doi.org/10.1080/23311940.2017.1303931

Menghua, T. (2011). Estimation and Comparison of Dynamic Hedging Ratio Models of Shanghai and Shenzhen 300 Index Futures: Empirical Study Based on Modified ECM-BGARCH $(1,1)$ Model. The Journal of Quantitative \& Technical Economics, 28(04), 137-149.

Miao-xin, C., \& Zhenlong, Z. (2008). The Impact of Short Selling Mechanism on the Volatility of the Securities market. Securities Market Herald.

Saffi, P., \& Sigurdsson, K. (2011). Price Efficiency and Short Selling. Review of Financial Studies, 24(3), 821-852. https://doi.org/10.1093/rfs/hhq124

Williams, R. J. (1991). Review: Philip Protter, Stochastic integration and differential equations- A new approach. Bulletin of the American Mathematical Society, 25, 170-180. https://projecteuclid.org/euclid.bams/1183657063

Xiaopeng, H. (2012). Research on the Influences of Margin Trading on the Volatility of Stock Market. Fudan University.

Xiaoshan, Z. (2011). Research on the Influence of Margin Trading on China Security Market. South China University of Technology

\section{Copyrights}

Copyright for this article is retained by the author(s), with first publication rights granted to the journal.

This is an open-access article distributed under the terms and conditions of the Creative Commons Attribution license (http://creativecommons.org/licenses/by/4.0/). 